Article

\title{
Effects of Environmental Traits and Landscape Management on the Biodiversity of Saproxylic Beetles in Mediterranean Oak Forests
}

\author{
Ana M. Cárdenas * (D), Patricia Gallardo $\mathbb{D}^{D}$, Ángela Salido $\mathbb{D}$ and José Márquez \\ Department of Zoology, Campus Rabanales, University of Córdoba, 14071 Córdoba, Spain; \\ b42gatop@uco.es (P.G.); b52sadea@uco.es (Á.S.); josemarser94@gmail.com (J.M.) \\ * Correspondence: ba1cataa@uco.es; Tel.: +34-957-218604
}

Received: 28 July 2020; Accepted: 25 November 2020; Published: 27 November 2020

check for updates

\begin{abstract}
This study assesses the effects of environmental traits and landscape management on the biodiversity of saproxylic beetles from "dehesas" located in Sierra Morena Mountains (Córdoba, Southern Iberian Peninsula). The dehesa is an open savanna-like landscape with mature/old trees scattered on a pasture cover where both living and dead wood are of great importance for the maintenance of macroinvertebrate fauna. The study was carried out in five plots, with different environmental features and management. A total of 137 branches belonging to the four main tree species present in the area were collected, classified, and kept under four different thermal conditions. From January to June 2019, the adult emergences were followed. A total of 466 saproxylic specimens of 31 species were obtained, 5 of them included in red lists of protected fauna. Two Bostrichidae species (Lichenophanes numida Lesne and Scobicia pustulata Fab.) and two Cerambycidae (Chlorophorus ruficornis Oliv. and Trichoferus fasciculatus Faldermann) are included in the "European Red List of Saproxylic Beetles"; and the Clerid Tillus ibericus Bahillo de la Puebla, López-Colón and García-Paris, is included in the "Red Book of Invertebrate of Andalucía". Differences were observed regarding the diversity and abundance among the plots and among the tree species from which the beetles emerged. Simple regression analyses revealed negative relationships between tree density/Buprestidae, livestock/Bostrichidae, and land use/Cerambycidae. Multivariant logistic regression analysis did not find significant relationships among environmental traits and saproxylic diversity. Results confirmed that dry wood was a main resource for the maintenance dehesas' biodiversity because it constitutes an ecological niche exploited by a significant set of saproxylic beetles belonging to the Bostrichidae, Buprestidae, and Cerambycidae families, in addition to other guilds of species, mainly Carabidae and Cleridae, which feed on the above-mentioned groups. Our results also support that increasing environmental temperature accelerates the development of Buprestidae, but this effect was not evident for the Bostrichidae species.
\end{abstract}

Keywords: biodiversity; Bostrichidae; Buprestidae; Cerambycidae; dehesa; environmental traits; landscape management; Mediterranean forests; saproxylic beetles

\section{Introduction}

The Mediterranean region holds a great bio-ecological heritage, thus determining its consideration as a "hot-spot" of world biodiversity [1]. However, Mediterranean forest landscapes have undergone a great transformation because of human activity throughout history. Wooded areas often suffer from isolation and fragmentation and are one of the most affected natural systems by annual variations in temperature and relative humidity because of the climate change. 
In addition, woodlands have traditionally been the subject of an intensive human management (e.g., coal industries, grazing, logging), leading to major changes in their spatial structure, composition, and dynamics.

In the southwest of the Iberian Peninsula, a peculiar "agrosilvopastoral" system has emerged as a result of the clearance and brushwood removal of the Mediterranean forest to introduce livestock: The "dehesa", an open savanna-like landscape with mature and old trees scattered in low density on a pasture cover [2]. It is the persistence of a simplified vegetation structure pattern, as well as its comprehensive management, which allows dehesas to have great socioeconomic importance and to sustain outstanding levels of biodiversity [3].

Part of this great ecological value lies in the wide variety of habitats and microhabitats represented in dehesas [4], where both the living structure of the woodland and dead wood are of great importance for the macroinvertebrate fauna. The dead wood or the fungi that proliferate on it are essential for the survival of saproxylic organisms [5]. These insects are a very diverse group and a chief piece in the trophic chain of forests due to their high biological diversification [5]. Many larvae are involved in the processes of decomposition and recycling of nutrients and the adults of several species may act as pollinator's agents [6].

Although the saproxylic fauna includes representatives of the main taxonomical groups of insects, Coleoptera is one of the orders with highest number of species, as more than half of the beetle families are in any way linked to dead or senescent wood [7].

Despite their crucial role in the ecosystem functioning and their consideration as bioindicators [8], a number of saproxylic species have undergone a sharp decline in their populations over the past century as a consequence of the intensification of human pressure, including the removal the dead wood $[9,10]$, which results in forest disturbances. In fact, a high percentage of them are currently threatened and included in red lists [11,12], and great research and conservation efforts must be made for ensuring their conservation $[13,14]$. In addition, saproxylic fauna is susceptible to be affected by the great recent environmental disturbance of climate change.

Climate change causes negative effects on living organisms, modifying the structure and composition of their communities, and prompting phenological asynchronies, which can lead to loss of biodiversity [15]. This environmental degradation affects, though in unequal ways and to different degrees, the different habitats on the planet including forest ecosystems [16-18]. The Mediterranean region and the Iberian Peninsula are likely to be severely affected by the climate change [19]. This vulnerability, which has been detected in different natural ecosystems, also affects singular ecosystems such as dehesas [19].

On the other hand, the responses of insects to climate change are complex and diverse and depend, among other factors, on their life cycle and ability to adapt. There are several studies assessing the effect of temperature on the development of some saproxylic coleoptera concluding that the increase of temperature leads to shorter developmental cycles of them, such as Buprestidae [20-23]; Cerambycidae [24]; Platypodinae, Scolytidae, and Bostrichidae [25-27]. As thermal increase linked to the global climate change in the Mediterranean area could be playing a significant role in shaping saproxylic beetle communities, the effect of environmental temperature on the emergence of adults was also aimed on this study.

The main goal of this study was to assess the effects of the environmental traits and landscape management on the biodiversity of saproxylic beetles' communities of different types of dehesa located in Sierra Morena Mountains (Córdoba, Southern Iberian Peninsula). Concretely, we analyzed: 1 . The saproxylic beetles linked to each host tree species; 2 . the relationships between landscape management and the saproxylic beetle's biodiversity; and 3. the effect of the environmental temperature on the emergence of adults. 


\section{Materials and Methods}

\subsection{Study Area}

This study was conducted in the Sierra Morena mountains (Córdoba, Southern Iberian Peninsula). In the area, the climate corresponds to the Mediterranean type and the landscape is dominated by cleared Mediterranean sclerophyll oak forests and pastures. Quercus ilex L., Q. suber L., and Q. faginea Lam. are the main components of the tree layer, but other species such as Olea europaea var. sylvestris L., Pinus pinea L., and Ceratonia siliqua L. are also present.

The thicket areas are mainly dominated by phanerophyte communities of shrubs, with xerophytic plant species like Pistacia lentiscus L., Erica sp., and diverse Cistus species [28].

For assessing the effects of the landscape traits and the anthropic practices on diversity of saproxylic beetles, five plots showing different environmental features were selected. To describe each sampling plot a total of 11 variables were considered: (i) Altitude, (ii) slope, (iii) orientation, (iv) shrub cover, (v) mean height of the shrub, (vi) shrub composition, (vii) tree cover, (viii) tree density, (ix) tree composition, (x) livestock presence, and (xi) other land uses. The vegetation fraction cover [29] was used to estimate plant cover and the distance to the nearest neighbor [30] to assess tree density.

\section{Description of Sampling Plots}

Plot 1: Country house Román-Pérez Bajo 1; 3756 $37.71^{\prime \prime}$ N, $4^{\circ} 42^{\prime} 57.91^{\prime \prime}$ W; 100 m; valley; no dominant orientation; shrub layer: $>5 \%$ cover, mean height of $92.8 \mathrm{~cm}$, dominated by Asparagus albus L., A. acutifolius L., Phlomis purpurea L., and Retama sphaerocarpa L.; tree layer: 25-50\% cover, 14.88 trees/ha, represented by Q. ilex $(80 \%)$, O. europaea $(15 \%)$, and Q. suber (5\%); horse and cattle farming; hunting and cork harvesting.

Plot 2: Country house Román-Pérez Bajo 2; 3756 $33.86^{\prime \prime}$ N, $4^{\circ} 42^{\prime} 59.58^{\prime \prime}$ W, 198 m; hillside; southeast; shrub layer: $75-100 \%$ cover, mean height of $95.7 \mathrm{~cm}$, dominated by A. albus, A. acutifolius, Nerium oleander L., Q. coccifera L., O. europaea, R. sphaerocarpa, and P. purpurea; tree layer: 50-75\% cover, 134.06 trees/ha, represented by Q. ilex (79\%), O. europaea (20\%), and C. siliqua (1\%); horse and cattle farming; no other land uses.

Plot 3: Rabanales Stream; $37^{\circ} 55^{\prime} 30.95^{\prime \prime} \mathrm{N}, 4^{\circ} 43^{\prime} 39.24^{\prime \prime} \mathrm{W}, 138 \mathrm{~m}$; valley; no dominant orientation; shrub layer: 5-25\% cover, mean height of $113.4 \mathrm{~cm}$, dominated by A. albus, A. acutifolius, P. purpurea, R. sphaerocarpa, Smilax aspera L., C. albidus L., Daphne gnidium L., Hedera helix L., N. oleander, P. lentiscus, and Rubus ulmifolius Schott.; tree layer: $25-50 \%$ cover, 41.53 trees/ha, represented by Q. ilex $(84 \%)$, Q. suber (10\%), O. europaea (4\%), and C. siliqua (2\%); sheep farming; cultivated land.

Plot 4: Periphery urban area Patriarca; 37 $54^{\prime} 25.57^{\prime \prime}$ N, 4 48'35.95” W, 183 m; valley; no dominant orientation; shrub layer: 75-100\% cover, mean height of $137 \mathrm{~cm}$, dominated by C. albidus, C. salviifolius L., P. purpurea, Asparagus sp., Genista hirsuta Vahl., D. gnidium, R. sphaerocarpa, P. lentiscus, and P. terebinthus L.; tree layer: $25-50 \%$ cover, 86 trees/ha, represented by Q. ilex $(80 \%)$, O. europaea $(5 \%)$, and C. siliqua (15\%); no land uses.

Plot 5: Country house Navalmilano; $38^{\circ} 15^{\prime} 0.84^{\prime \prime} \mathrm{N}, 4^{\circ} 38^{\prime} 37.98^{\prime \prime} \mathrm{W}, 737 \mathrm{~m}$; valley; no dominant orientation; shrub layer missed; tree layer: $50-75 \%$ cover, 47.44 trees/ha, represented by Q. ilex (98\%); cattle and pig farming; firewood pruning.

\subsection{Field and Laboratory Work}

Fieldwork was done from December 2018 to February 2019, fitting to the time of the lowest activity of saproxylic beetles. It consisted of collecting and defoliating dry branches of several tree species. All the branches used in the study came from the top of the tree and were completely dry at the time of pruning. The section of the branches selected for the study was of $1 \mathrm{~m}$ length and between 2 and $6 \mathrm{~cm}$ $\varnothing$ approximately.

A pole saw was used to prune the less accessible branches. Once cut, the secondary branches were removed, and the branches to study were referenced, labeled, and individually packed in transparent 
plastic bags. The number of branches of each species depended on the availability in the field (Table 1 ). A total of 137 branches were collected: 69 from Q. ilex, 20 from Q. suber, 32 from O. europaea, and 16 from $C$. siliqua. In the laboratory, the branches were distributed in four similar groups.

Table 1. Number of branches of each tree species collected in each sampling plot (P).

\begin{tabular}{ccccc}
\hline Plot & Q. ilex & Q. suber & O. europaea & C. siliqua \\
\hline P1 & 16 & 12 & 8 & 0 \\
P2 & 12 & 0 & 8 & 8 \\
P3 & 9 & 8 & 8 & 0 \\
P4 & 12 & 0 & 8 & 8 \\
P5 & 20 & 0 & 0 & 0 \\
\hline
\end{tabular}

Three of them were placed in controlled cultured rooms at different temperatures. The fourth group was kept outside, under environmental conditions (Table 2). Temperature was weekly monitored to each trial.

Table 2. Average temperature $\left({ }^{\circ} \mathrm{C}\right) \pm$ standard error $(\mathrm{SE})$ and number of branches of each tree species used in the trials $(\mathrm{T})$.

\begin{tabular}{cccccc}
\hline \multirow{2}{*}{ Trial } & \multirow{2}{*}{ Average Temperature $\left({ }^{\circ} \mathbf{C}\right)$} & \multicolumn{4}{c}{ Number of Branches } \\
\cline { 3 - 5 } & & Q. ilex & Q. suber & O.europaea & C. siliqua \\
\hline T 1 & $20.72 \pm 1.57$ & 18 & 5 & 8 & 4 \\
T 2 & $22.85 \pm 0.42$ & 17 & 5 & 8 & 4 \\
T 3 & $25.40 \pm 0.32$ & 17 & 5 & 8 & 4 \\
T 4 & $18.54 \pm 1.31$ & 17 & 5 & 8 & 4 \\
\hline
\end{tabular}

To study the emergencies of saproxylic fauna, branches were examined biweekly, from 1 January to 30 July 2019. Upon detecting sawdust in the bags because of the activity of the insects, we looked carefully inside them and lightly shook the branches to collect the recent emerged individuals. In this way, we also knew to which tree species and to which plot each counted individual corresponded. When possible, live specimens were identified, censused, and released.

The specimens that could not be identified were preserved in ethanol $70 \%$ for later classification. The taxonomical criteria followed agrees with those of Bahillo de la Puebla and López-Colón [31] and Bahillo de la Puebla et al. [32] in the case of Cleridae family; Cobos [33] and Verdugo [34] for Buprestidae; Ortuño and Toribio [35] for Carabidae; Villiers [36] and Vives [37] for Cerambycidae; and Bahillo de la Puebla et al. [38] for Bostrichidae.

\subsection{Data Analysis}

To check preferences of saproxylic beetles for the species of the host tree, a generalized linear mixed model (GLMM) was performed, considering the branch as the sampling unit, the number of specimens for each of the families as the categorical factor, and the sampling plot as the random factor. The interaction between tree species and sampling plot was also accomplished, and the post hoc test within the mixed analysis was developed to check for differences among the level of categorical variables.

To faunistically typify the saproxylic community linked to each sampling plot, species richness $(\mathrm{S})$, species abundance $(\mathrm{N})$, Shannon diversity $\left(\mathrm{H}^{\prime}\right)$, dominance $(\mathrm{D})$, and evenness $(\mathrm{J})$ indices were calculated. To assess differences in saproxylic fauna coming from different plots or tree species, paired comparison tests (bootstraps) were performed. The bootstrapping procedure resampled a single dataset to create many simulated datasets [39]. This process involved drawing random samples from the original dataset and computing a few diversity indices for two samples, and then comparing the diversities using random permutations. The bootstrapping option (giving a $95 \%$ confidence interval) was based on 2000 replicates. 
Affinity among communities was verified by both presence-absence and the abundance of species, and the Jaccard similarity coefficients and the Euclidean distances were calculated to obtain the respective dendrograms [40].

To verify the effect of temperature on the chronology of emergencies, a generalized linear model (GLM), for count variables and Poisson distribution, was performed with the time as the covariate (taken as number of fortnights since the monitoring started) and the temperature category as the independent factor. The iteratively reweighted least squares (IRLS) algorithm for maximum likelihood estimation was used. The dispersion parameter $\varphi$ was fixed at $\varphi=1$ for the Poisson distribution.

To test the relationships between the environmental traits recorded at each sampling plot and saproxylic beetles, a multivariate logistic regression analysis was performed [41], considering as dependent variable the presence/absence of species, and altitude, slope, orientation, shrub cover, tree density, livestock presence, and other land uses as the independent ones.

Prior, binary regression analysis between the data of saproxylic species (independently analyzed for each family) and the independent variables were calculated, considering the Pearson correlation or Spearman correlation for qualitative or quantitative data, respectively [42]. Selection of quantitative variables to be incorporated in the multiple tests was designated according to the value of the Spearman correlation coefficient. If this value was significant, the variable to be incorporated into the model was the one that had obtained the greatest significance in the simple regression analysis. If the test resulted in no significance, both variables were included in the multivariate model.

All statistical tests were conducted with $\alpha=0.05$. In addition, to make a more accurate interpretation of results, the Bonferroni's adjustment of $p$-value for multiple comparisons was considered testing significance in the logistic regression.

Calculations were performed using the SP Statistical Software [43] and the PAST Software (v.3.25 [44]).

\section{Results}

\subsection{Faunistic Results}

A total of 466 individuals of saproxylic beetles belonging to 31 species and 5 families (comprehensive taxonomic relation in Supplementary material Table S1) were identified (Table 3).

Table 3. Species of saproxylic beetles recorded, indicating for each of them the number of specimens, the sampling plot of provenance $(\mathrm{P})$, and the family they belong to. In bold are the species included in red lists.

\begin{tabular}{|c|c|c|c|c|c|c|c|c|c|c|c|c|c|}
\hline Family & P1 & P2 & P3 & P4 & P5 & Total & Family & P1 & P2 & P3 & P4 & P5 & Total \\
\hline \multicolumn{7}{|c|}{ Bostrichidae } & \multicolumn{7}{|c|}{ Carabidae } \\
\hline L. numida & 1 & 0 & 1 & 0 & 0 & 2 & C. bifasciatus & 0 & 0 & 0 & 1 & 0 & 1 \\
\hline S. pustulata & 0 & 0 & 1 & 2 & 0 & 3 & Dromius sp. & 0 & 0 & 0 & 3 & 0 & 3 \\
\hline S. sexdentatum & 0 & 0 & 0 & 92 & 0 & 92 & M. luctuosus & 10 & 0 & 0 & 0 & 1 & 11 \\
\hline T. impressum & 0 & 0 & 0 & 231 & 1 & 232 & P. linearis & 0 & 0 & 0 & 0 & 1 & 1 \\
\hline - & - & - & - & - & - & - & P. obtusus & 0 & 0 & 0 & 0 & 1 & 1 \\
\hline \multicolumn{7}{|c|}{ Buprestidae } & T. obtusus & 2 & 0 & 1 & 0 & 0 & 3 \\
\hline A. adspersula & 12 & 2 & 2 & 0 & 3 & 19 & $-\ldots$ & - & - & - & - & - & - \\
\hline A. degener & 1 & 0 & 0 & 1 & 12 & 14 & \multicolumn{7}{|c|}{ Cerambycidae } \\
\hline A. angustulus & 1 & 0 & 0 & 0 & 0 & 1 & C. ruficornis & 0 & 0 & 0 & 1 & 0 & 1 \\
\hline A. graminis & 4 & 0 & 1 & 0 & 0 & 5 & P. timida & 0 & 0 & 1 & 5 & 0 & 6 \\
\hline A. hastulifer & 1 & 0 & 0 & 0 & 0 & 1 & T. fasciculatus & 0 & 1 & 0 & 4 & 0 & 5 \\
\hline A. laticornis & 1 & 0 & 1 & 0 & 0 & 2 & - & - & - & - & - & - & - \\
\hline Agrilus sp. & 1 & 0 & 0 & 0 & 0 & 1 & \multicolumn{7}{|c|}{ Cleridae } \\
\hline A. dimidiata & 0 & 1 & 0 & 0 & 0 & 1 & D. albofasciatus & 0 & 0 & 0 & 1 & 0 & 1 \\
\hline A. hungarica & 0 & 0 & 1 & 0 & 1 & 2 & O. domesticus & 1 & 0 & 0 & 1 & 1 & 3 \\
\hline A. millefolii & 32 & 1 & 7 & 0 & 0 & 40 & T. univittatus & 0 & 0 & 0 & 7 & 0 & 7 \\
\hline A. thalassophila & 0 & 0 & 0 & 1 & 0 & 1 & T. ibericus & 0 & 1 & 0 & 0 & 2 & 3 \\
\hline A. umbellatarum & 0 & 0 & 0 & 2 & 0 & 2 & T. leucopsideus & 0 & 0 & 1 & 0 & 0 & 1 \\
\hline - & - & - & - & - & - & - & T. octopunctatus & 0 & 0 & 0 & 0 & 1 & 1 \\
\hline
\end{tabular}


Five species are included in red lists of protected fauna. Two Bostrichidae species (L. numida and S. pustulata) and two Cerambycidae (C. ruficornis and T. fasciculatus) are included in the "European Red List of Saproxylic beetles"; and the Cleridae T. ibericus is included in the "Red book of Invertebrate of Andalucía".

In terms of abundance, the Bostrichidae stood out ( $70.60 \%$ of individuals), while the most diverse family was Buprestidae (12 species). At the opposite end was the Cerambycidae (2.58\% of individuals and 3 species).

\subsection{Saproxylic Fauna and Host Tree}

The species of saproxylic beetles linked to each tree species and their respective abundances are shown in Table 4. The highest number of species was found in Q. ilex (19), while the lowest one was found in O. europaea (5). The highest number of individuals (344) was found in C. siliqua.

Table 4. Species of saproxylic beetles recorded indicating for each of them the number of specimens, the tree species of provenance, and the family they belong to. (Cs: C. siliqua; Oe: O. europaea; Qi: Q. ilex; Qs: Q. suber).

\begin{tabular}{|c|c|c|c|c|c|c|c|c|c|}
\hline Family & $Q i$ & Qs & $O e$ & Cs & Family & $Q i$ & Qs & $O e$ & Cs \\
\hline \multicolumn{5}{|c|}{ Bostrichidae } & \multicolumn{5}{|c|}{ Carabidae } \\
\hline L. númida & 1 & 1 & 0 & 0 & C. bifasciatus & 1 & 0 & 0 & 0 \\
\hline S. pustulata & 0 & 1 & 0 & 2 & Dromius sp. & 0 & 0 & 2 & 1 \\
\hline S. sexdentatum & 0 & 0 & 0 & 92 & M. luctuosus & 1 & 10 & 0 & 0 \\
\hline T. impressum & 1 & 0 & 0 & 231 & P. linearis & 1 & 0 & 0 & 0 \\
\hline \multicolumn{5}{|c|}{ Buprestidae } & P. obtusus & 1 & 0 & 0 & 0 \\
\hline A. adspersula & 19 & 0 & 0 & 0 & T. obtusus & 0 & 3 & 0 & 0 \\
\hline A. degener & 14 & 0 & 0 & 0 & \multicolumn{5}{|c|}{ Cerambycidae } \\
\hline A. angustulus & 0 & 1 & 0 & 0 & C. ruficornis & 1 & 0 & 0 & 0 \\
\hline A. graminis & 0 & 4 & 1 & 0 & P. timida & 1 & 0 & 0 & 5 \\
\hline A. hastulifer & 0 & 1 & 0 & 0 & T. fasciculatus & 2 & 0 & 0 & 3 \\
\hline A. laticornis & 1 & 1 & 0 & 0 & \multicolumn{5}{|c|}{ Cleridae } \\
\hline Agrilus sp. & 1 & 0 & 0 & 0 & D. albofasciatus & 0 & 0 & 0 & 1 \\
\hline A. dimidiata & 0 & 0 & 1 & 0 & O. domesticus & 3 & 0 & 0 & 0 \\
\hline A. hungarica & 1 & 0 & 1 & 0 & T. univittatus & 0 & 0 & 0 & 7 \\
\hline A. millefolii & 40 & 0 & 0 & 0 & T. ibericus & 3 & 0 & 0 & 0 \\
\hline A. thalassophila & 0 & 0 & 1 & 0 & T. leucopsideus & 1 & 0 & 0 & 0 \\
\hline A. umbellatarum & 0 & 0 & 0 & 2 & T. octopunctatus & 1 & 0 & 0 & 0 \\
\hline
\end{tabular}

The GLMM analysis performed considering the number of specimens emerged from to the different tree species fully supports these differences in host tree selection $(\mathrm{F}=61,85 ; p<0.0001$; post-hoc tests are shown in Supplementary material Table S2).

From data shown in Table 4, the indices defining the beetle community linked to each tree species have been obtained and the subsequent statistical comparisons have been performed (Table 5).

The bootstrapping comparisons found significant differences in the abundance of saproxylic species, especially between $C$. siliqua and the rest of the tree species. These differences are rendered in terms of dominance and Shannon indices.

Highlighting only the most remarkable results, it should be mentioned that there were quantitative differences among all the tree species, while from a qualitative point of view, only the carob tree differed significantly from the rest (Table 5).

Graphically plotting affinities by the qualitative grouping dendrogram, the olive tree was the most discrepant species, while by considering the quantitative component of the respective communities, the carob tree firstly segregated due to the great and almost exclusive presence of the Bostrichidae T. impressum (Figure 1A,B). 
Table 5. Richness (species number), abundance (specimen number), dominance (Simpson's index), diversity (Shannon-Wiener $\mathrm{H}^{\prime}$ ), evenness indices for saproxylic communities linked to each tree species (Cs: C. siliqua; Oe: O. europaea; Qi: Q. ilex; Qs: Q. suber), and paired comparisons between them. $p=$ bootstrapping comparisons. Values with statistical significance are highlighted in bold type.

\begin{tabular}{cccccccccc}
\hline & Oe & Cs & $\boldsymbol{P}$ & Oe & Qi & $\boldsymbol{P}$ & O & Qs & $\boldsymbol{P}$ \\
\hline Richness & 5 & 9 & 0.99 & 5 & 19 & 0.40 & 5 & 8 & 0.84 \\
Abundance & 6 & 344 & $\mathbf{0}$ & 6 & 95 & $\mathbf{0}$ & 6 & 22 & $\mathbf{0}$ \\
Dominance & 0.22 & 0.52 & 0.09 & 0.22 & 0.24 & 0.85 & 0.22 & 0.27 & 0.71 \\
Shannon & 1.56 & 0.90 & 0.09 & 1.56 & 1.92 & 0.87 & 1.56 & 1.64 & 0.93 \\
Evenness & 0.95 & 0.27 & 0.42 & 0.95 & 0.36 & $\mathbf{0 . 0 3}$ & 0.95 & 0.64 & $\mathbf{0 . 0 6}$ \\
\hline & $\mathbf{Q i}$ & $\mathbf{C s}$ & $\boldsymbol{P}$ & $\mathbf{Q i}$ & $\mathbf{Q s}$ & $\boldsymbol{P}$ & $\mathbf{C s}$ & $\mathbf{Q s}$ & $\boldsymbol{P}$ \\
\hline Richness & 19 & 9 & 0.18 & 19 & 8 & 0.22 & 9 & 8 & 1 \\
Abundance & 95 & 344 & $\mathbf{0}$ & 95 & 22 & $\mathbf{0}$ & 344 & 22 & $\mathbf{0}$ \\
Dominance & 0.24 & 0.52 & $\mathbf{0 . 0 0 1}$ & 0.24 & 0.27 & 0.68 & 0.52 & 0.27 & $\mathbf{0 . 0 1 8}$ \\
Shannon & 1.92 & 0.90 & $\mathbf{0 . 0 0 1}$ & 1.92 & 1.64 & 0.53 & 0.90 & 1.64 & $\mathbf{0 . 0 0 8}$ \\
Evenness & 0.36 & 0.27 & 0.82 & 0.36 & 0.64 & 0.27 & 0.27 & 0.64 & 0.59 \\
\hline
\end{tabular}

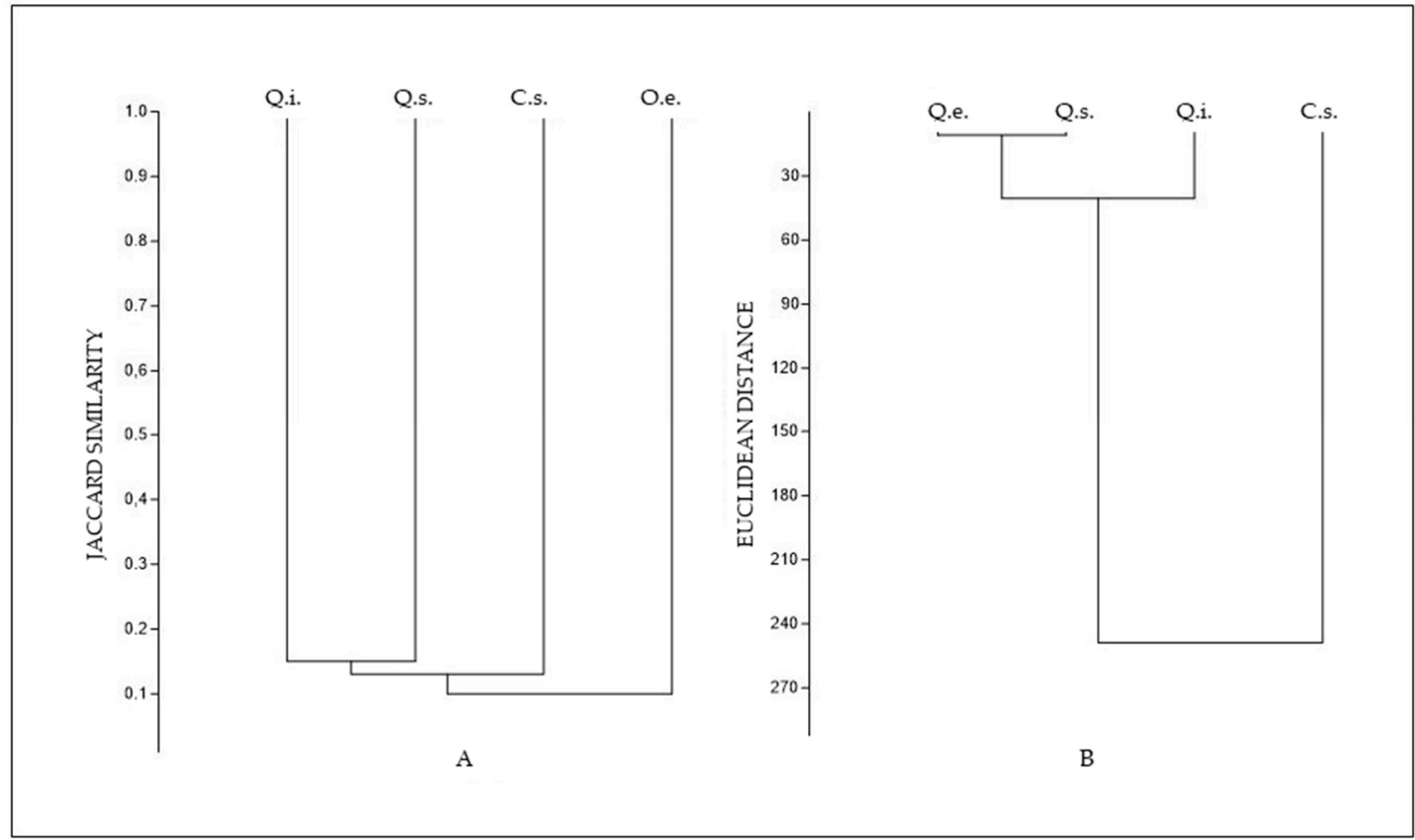

Figure 1. Grouping dendrograms for tree species. (A) Qualitative grouping dendrogram obtained with the Jaccard's similarity index; (B) quantitative grouping dendrogram obtained with Euclidean distances. O.e.: O. europaea; C.s.: C. siliqua; Q.i.: Q. ilex; Q.s.: Q. suber.

\subsection{Saproxylic Fauna and Environmental Features}

Discriminating among sampling plots (Table 3), P4 resulted as the most suitable to saproxylic beetles, holding 14 species and 352 individuals, i.e., more than $75 \%$ of the specimens and $28 \%$ of the species of the overall sample. The abundance of two species was noticeable: S. sexdentatum and T. impressum, which were the most recurrent in our study. Conversely, P2 was faunistically the poorest plot with only 5 species and 6 individuals.

Results referred to each plot in terms of ecological indices (diversity, dominance, and evenness, Table 6) support the prior statements. In the remaining plots, the abundance of saproxylic beetles was remarkably diminished with respect to $\mathrm{P} 4$, but the representativeness by families of beetles and, to a lesser extent, by the number of species, were quite balanced. 
Table 6. Richness (species number), abundance (specimens' number), dominance (Simpson's index), diversity (Shannon-Wiener $\mathrm{H}^{\prime}$ ), evenness indices for saproxylic communities linked to each sampling plot $(\mathrm{P})$ and paired comparisons between them. $p=$ bootstrapping comparisons. Values with statistical significance are highlighted in bold type.

\begin{tabular}{ccccccccccccc}
\hline & $\mathbf{P 1}$ & $\mathbf{P 2}$ & $\boldsymbol{P}$ & $\mathbf{P 1}$ & $\mathbf{P 3}$ & $\boldsymbol{P}$ & $\mathbf{P 1}$ & $\mathbf{P 4}$ & $\boldsymbol{p}$ & $\mathbf{P 1}$ & $\mathbf{P 5}$ & $\boldsymbol{P}$ \\
\hline Richness & 12 & 5 & 0.67 & 12 & 10 & 0.96 & 12 & 14 & 0.99 & 12 & 10 & 0.89 \\
Abundance & 67 & 6 & $\mathbf{0}$ & 67 & 17 & $\mathbf{0}$ & 67 & 352 & $\mathbf{0}$ & 67 & 25 & $\mathbf{0}$ \\
Dominance & 0.29 & 0.22 & 0.64 & 0.29 & 0.21 & 0.42 & 0.29 & 0.50 & $\mathbf{0 . 0 0 1}$ & 0.29 & 0.27 & 0.71 \\
Shannon & 1.66 & 1.56 & 0.93 & 1.66 & 1.95 & 0.47 & 1.66 & 1.01 & $\mathbf{0 . 0 0 3}$ & 1.66 & 1.78 & 0.66 \\
Evenness & 0.44 & 0.95 & 0.05 & 0.44 & 0.70 & 0.34 & 0.44 & 0.19 & 0.13 & 0.44 & 0.60 & 0.50 \\
\hline & $\mathbf{P 2}$ & $\mathbf{P 3}$ & $\boldsymbol{p}$ & $\mathbf{P 2}$ & $\mathbf{P 4}$ & $\boldsymbol{P}$ & $\mathbf{P 2}$ & $\mathbf{P 5}$ & $\boldsymbol{P}$ & $\mathbf{P 3}$ & $\mathbf{P 4}$ & $\boldsymbol{P}$ \\
\hline Richness & 5 & 10 & 0.31 & 5 & 14 & 0.97 & 5 & 10 & 0.57 & 10 & 14 & 1 \\
Abundance & $\mathbf{6}$ & 17 & $\mathbf{0}$ & 6 & 352 & $\mathbf{0}$ & 6 & 25 & $\mathbf{0}$ & 17 & 352 & $\mathbf{0}$ \\
Dominance & 0.22 & 0.21 & 0.94 & 0.22 & 0.50 & 0.09 & 0.22 & 0.27 & 0.75 & 0.21 & 0.50 & $\mathbf{0 . 0 2 9}$ \\
Shannon & 1.56 & 1.95 & 0.59 & 1.56 & 1.01 & 0.29 & 1.56 & 1.78 & 0.82 & 1.95 & 1.01 & $\mathbf{0 . 0 0 3}$ \\
Evenness & 0.95 & 0.70 & 0.13 & 0.95 & 0.19 & 0.18 & 0.95 & 0.60 & 0.06 & 0.70 & 0.19 & 0.42 \\
\hline & $\mathbf{P 3}$ & $\mathbf{P 5}$ & $\boldsymbol{P}$ & $\mathbf{P 4}$ & $\mathbf{P 5}$ & $\boldsymbol{P}$ & & & & & & \\
\hline Richness & 10 & 10 & 1 & 14 & 10 & 1 & & & & & & \\
Abundance & 17 & 25 & $\mathbf{0}$ & 352 & 25 & $\mathbf{0}$ & & & & & & \\
Dominance & 0.21 & 0.27 & 0.38 & 0.50 & 0.27 & $\mathbf{0 . 0 2 7}$ & & & & & & \\
Shannon & 1.95 & 1.78 & 0.61 & 1.01 & 1.78 & $\mathbf{0 . 0 1 3}$ & & & & & & \\
Evenness & 0.70 & 0.60 & 0.34 & 0.19 & 0.60 & 0.39 & & & & & & \\
\hline
\end{tabular}

Paired comparison of the indices' descriptors of the communities belonging to the different sampling plots showed significant differences in terms of abundance in all the cases. In addition, P4 differed in dominance and diversity of species (Table 6).

For graphically supporting affinity among communities, both presence-absence and abundance of species were considered to obtain the respective dendrograms. After checking affinities in the matrix of quantitative data, the graph obtained in Figure 2A revealed no aggrupation above $50 \%$ affinity.

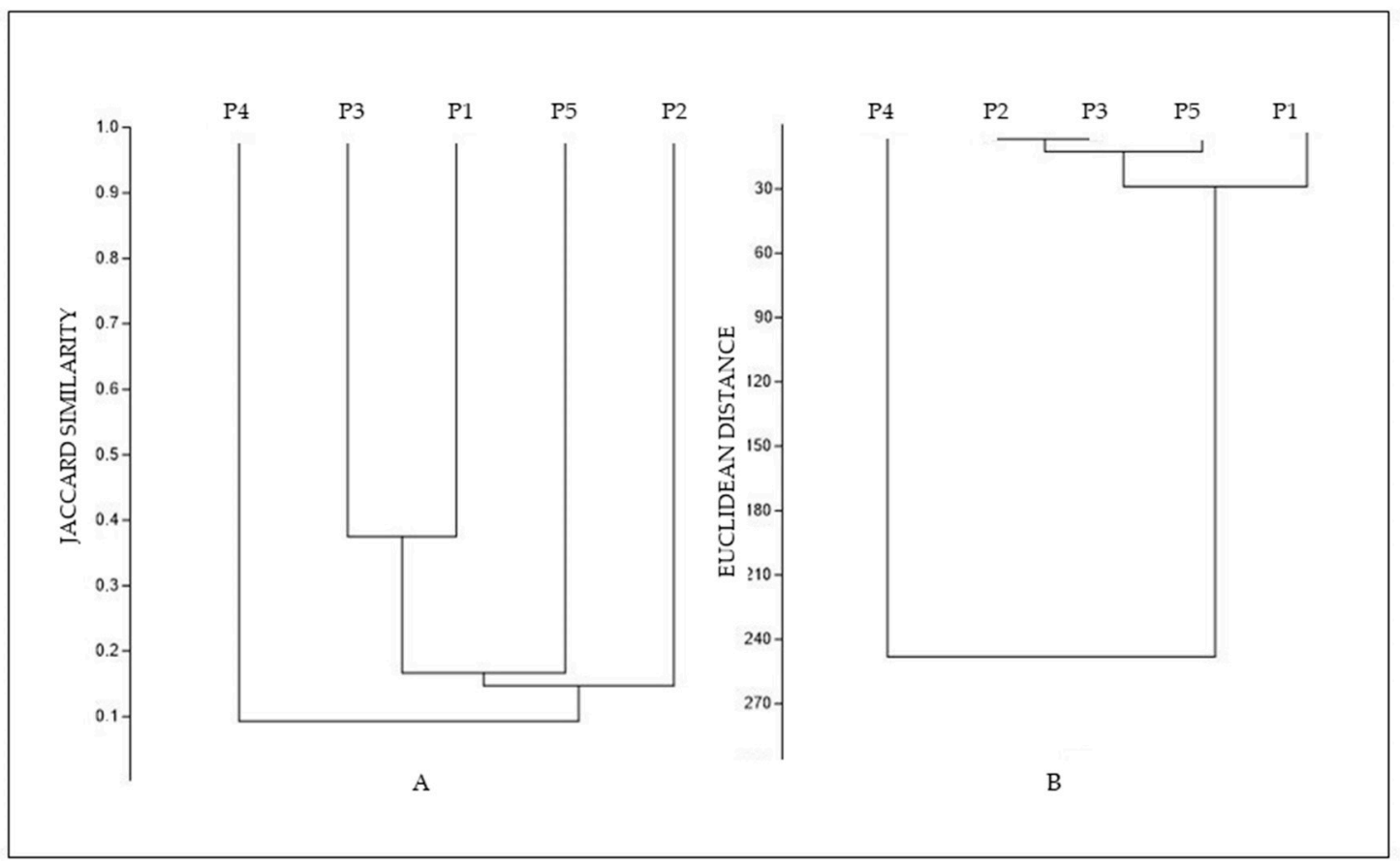

Figure 2. Grouping dendrograms for sampling plots. (A) Qualitative grouping dendrogram obtained with the Jaccard's Similarity index; (B) Quantitative grouping dendrogram obtained with Euclidean distances. P1, P2, P3; P4, P5 are sampling plots. 
The greatest similarity barely reached $40 \%$ and it was established between P1 and P3, while P4 segregated from the set, with less than $15 \%$ similarity. In the quantitative dendrogram showed in Figure 2B, the discrepancy between the saproxylic fauna of $\mathrm{P} 4$ and that of the other studied areas was confirmed, which, in turn, formed a much more homogeneous group with more than $80 \%$ affinity.

Simple logistic regression among the nominal variable (presence/absence of saproxylic) and the environmental features revealed several negative relationships (Supplementary material Tables S3 and S4): A negative correlation between tree density and presence of Buprestidae $(\beta=-0.014 ; p=0.063)$; a negative correlation between presence of Bostrichidae and livestock ( $\beta=-2.565 ; p=0.052)$; and a negative correlation between land use and presence of Cerambycidae ( $\beta=-2.773 ; p=0.043)$.

Before proceeding with the multivariate logistic regression analysis, the correlation between the quantitative variables of tree density and altitude was explored. The Spearman index found a significant correlation $\left(\mathrm{r}_{\mathrm{s}}=0.7 ; p=0\right)$, and, in consequence, only one of these variables was considered depending on its respective signification values in the simple regression performed by breaking down the analysis by beetle's family (Supplementary material Table S5).

The results of the multivariant logistic regression uniquely found a significant negative correlation between the variables of tree density and presence of Buprestidae ( $\beta=-0.055 ; p=0.048)$; this value lost significance when the Bonferroni's $p$-adjustment was considered (lower 0.05 to 0.0071 ).

\subsection{Effect of the Environmental Temperature on the Chronology of Adult Emergencies}

For most of the species, the number of individuals that emerged from the different trials had been scarce and did not allow us to perform a detailed phenological analysis (fully fortnightly data of number of individuals of each species are shown in Supplementary material Tables S6-S9). Nevertheless, some trends could be observed at a higher taxonomic level. Overall, the results indicated that environmental temperature affected the life cycle of saproxylic beetles, speeding up their emergency as adults. This effect was quite noticeable for the species of Buprestidae, which in the trial performed under environmental conditions emerged in spring (first half of May), while in the rest of the trials the first observations were earlier (February-March), particularly at a temperature of $25^{\circ} \mathrm{C}$. Only in the case of Bostrichidae were there two species, $S$. sexdentatum and T. impressum, with enough individuals to statistically analyze the course of emergences in the different experimental conditions. In both species, the emergency interval was quite delimited, overlapping for all the trials. In addition, a phenological gap was observed in the emergency time of these species, S. sexdentatum (middle spring) being earlier than T. impressum (early summer; Figures 3 and 4, respectively).

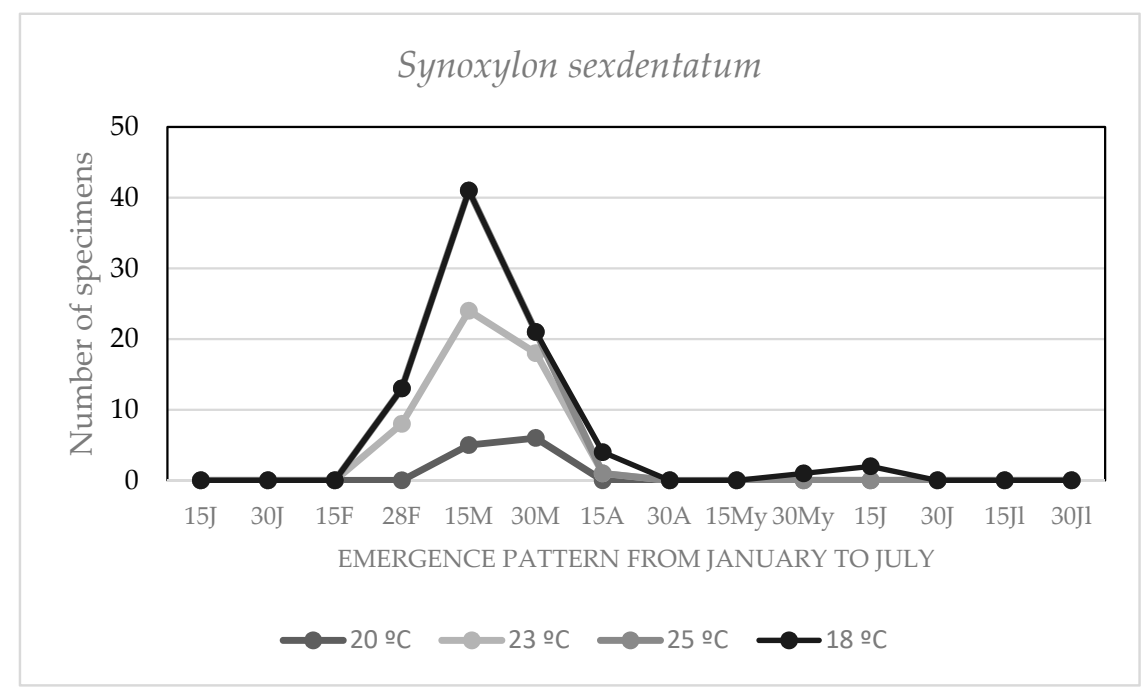

Figure 3. Emergence pattern of Synoxylon sexdentatum at different temperatures ${ }^{\circ}{ }^{\circ} \mathrm{C}$ from January to July. 


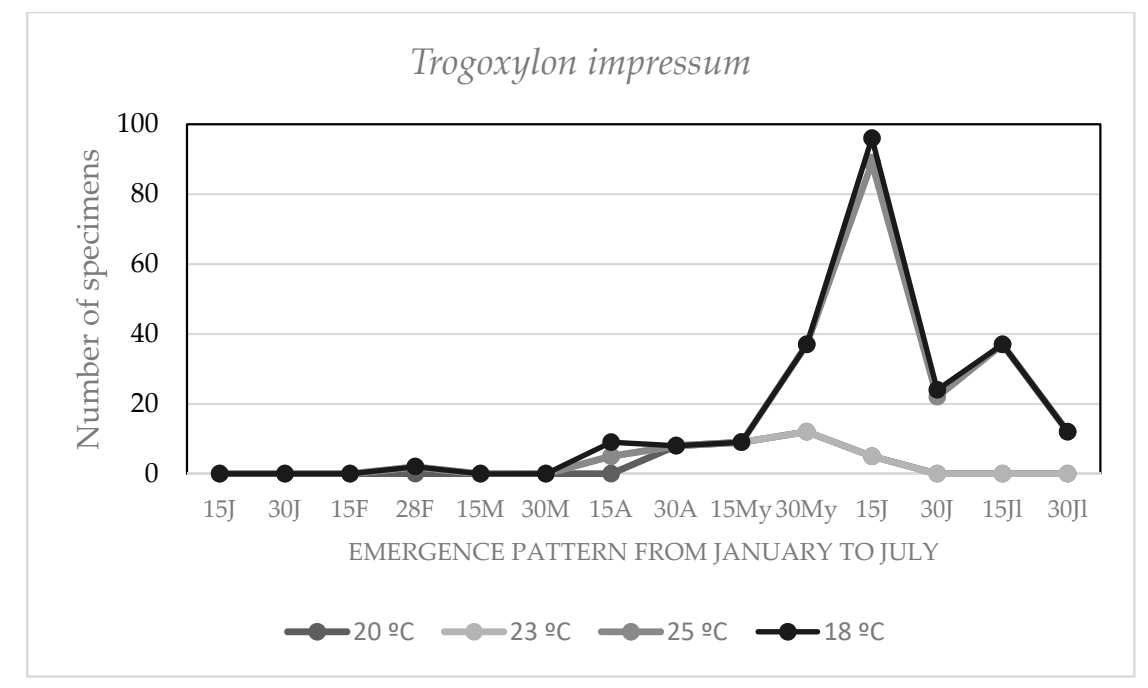

Figure 4. Emergence pattern of Trogoxylon impressum at temperatures ${ }^{\circ} \mathrm{C}$ from January to July.

These observations were validated by the GLM analysis: The model dis no find significant differences in the temporal course of emergencies at different temperatures for any of the species $(\mathrm{G}=0.375 ; p=0.579$ for $S$. sexdentatum; $\mathrm{G}=0.378 ; p=0.538$ for $T$. impressum).

The number of specimens of Cerambycidae was very scarce (total 6) and the emergence occurred in April-May, except in the environmental conditions trial where no specimens were obtained throughout the entire follow-up.

As for the predatory taxa, we considered firstly the Carabids, highlighting that most of the specimens were obtained in environmental conditions and later winter (January-March). Finally, the Cleridae appeared irregularly and scarcely in temperature-controlled trials, while in environmental conditions they showed the maximum of emergencies in May (Supplementary material Tables S6-S9).

\section{Discussion}

The results obtained support that dry wood available in dehesas constitutes an essential trophic resource for a set of saproxylic beetles belonging to the Bostrichidae, Buprestidae, and Cerambycidae families. Agreeing with Grove [45] and Jonnson et al. [46], we also verified that the ecological niche provided by dry branches was exploited by other guilds of species, mainly Carabidae and Cleridae, which feed on the above-mentioned groups.

Considering that the life cycle of many endophyte coleopterans could be extended for a few years, the number of saproxylic species recorded during six months of follow-up confirms that dehesa is a singular ecosystem also playing a chief role in terms of saproxylic beetles' biodiversity. Different authors reached similar conclusions, highlighting the remarkable diversity of saproxylic organisms in the Mediterranean oak forest $[4,47,48]$.

Concerning our results, the major contribution of Bostrichidae is clearly attributable to the large presence of T. impressum and S. sexdentatum. These species have been found in $C$. siliqua branches coming from the peri-urban area of "Patriarca", where this vegetal species is abundant. Literature about the trophic preferences of these species of Bostrichidae indicates that they could be associated with Ficus carica L. [49], with a variety of plant species such as a Cercis, Eucalyptus, Ficus, Pistacia, Quercus, or Tamarix [50] also including the carob tree. Trophic plasticity has been also mentioned by Bahillo de la Puebla et al. [38] when referring to the polyphagous nature of both beetle species.

The sampling plot with the lowest abundance of saproxylic beetles corresponded to an area with a wide bush cover, mainly composed of O. europaea, in the country house Román-Pérez Bajo 2 (P2). This contrasted with the abundance obtained in the adjacent sampling plot-the country house Román-Pérez Bajo 1 (P1) where the bush cover did not exceed 5\% of the studied surface. These 
results agreed with those obtained by Ramírez-Hernández et al. [4] in pastures in the center of the Iberian Peninsula, where the greatest wealth of saproxylic beetles was found in areas with scarce shrubs. In addition, several studies performed in European forests showed that the landscape structure was a decisive factor for the presence of saproxylic beetles: Open areas contain greater amount of accumulated dead wood, favoring saproxylic populations [51-53]. According to these statements, our results of the simple logistic regression analysis showed that the presence of Buprestids was inversely related to tree density. These results also coincided with those pointed out by Ramilo [48] who obtained lower wealth of saproxylic beetles in areas with high plant density.

Regarding the relationship between the abundance of saproxylic beetles and the tree species, clear differences have been observed as a result of the high number of T. impressum specimens emerged from the carob branches. The trophic versatility of this beetle is not extensible to other xylophagous species, most frequently associated with oak species. The lack of competitors also explained the lowest diversity recorded in C. siliqua compared to the rest of the tree species studied. On the other hand, only six specimens belonging to five species of Coleoptera emerged from the O. europaea branches. The structural simplicity and smaller size of this tree species which provided fewer microhabitats and niches could explain the low amount of saproxylic associated. In this sense, Micó et al. [54] concluded that cracks, wounds, and especially hollows are key elements for xylophagous beetles since the organic matter accumulated in these structures, along with own wood, provide a continuous food resource for saproxylic fauna.

In respect to the saproxylic richness-host tree species linkage, the results showed the highest number of species was obtained from Quercus branches, particularly in the case of the Buprestidae family. Similar conclusions were supported in literature: Gallardo and Cárdenas [14] pointed to Q. ilex and Q. suber; Recalde and San Martín [55] to Q. faginea and Q. rotundifolia Lam.

Related to the phenology of saproxylic species, although the number of emergencies was, in general, low, joint results supported that environmental temperature influences the development of Buprestidae. The earliest emergence of adults was observed from branches maintained at the highest average temperature, preempting almost a month and a half with respect to environmental conditions. A similar emergence pattern was observed in Coraebus florentinus Herb. [22]. Myers et al. [20] also detected variations in the life cycles and survival of $A$. planipennis $F$. related to the same factor. Considering the positive effect of temperature on xylophagous Buprestidae development, it is worth considering the incidence of the thermal rise linked to global climate change on the population size and propagation of these species. In this context, Lindner et al. [56] and Netherer and Schopf [57] studied the effect in A. biguttatus Fab., establishing that warmer summers offer greater opportunities for physiological development: Increased drought provides a greater availability of dry wood and, consequently, detrimental effects of this pest would be more severe. Other studies on Agrilus species reveal changes in geographic distribution, some of them related to the rising temperature [58].

However, the effect of temperature was less evident on the Bostrichidae development. Two emergency maxima were recorded throughout the follow-up, mainly attributable the earlier prompting of $S$. sexdentatum and the later of T. impressum, regardless of thermal conditions. In relation to these results, it could be considered that, in addition to abiotic factors, there were other aspects implicated in the life cycle of these insects, which influence their temporal patterns [59-61]. Powell and Logan [62] mention that maintaining an adaptive seasonality, with life cycles and periods of activity that take place at specific times of the year, is a fundamental ecological requirement for many ectothermic organisms.

In addition, body size was a determinant factor in insects' development. Several studies have found a decisive role of this feature in the duration of the larval period [63,64]. Gallardo and Cárdenas [14] indicate that for smaller species of jewel beetles, such as A. angustulus and A. millefolii, the larval period was shorter than in other species with larger body size, such as A. hungarica. Finally, Scriven et al. [65] combined both factors, since they related the size of the species with life cycles and temperature, referring to the fact that larger sizes require longer exposure to high temperatures to start activity, while smaller sizes do not require such exposure. 
The low number of Cerambycidae obtained in our trials could be explained by the mentioned combination of factors. Indeed, the late emergencies of these insects, which coincided with the end of spring, only occurred under higher temperature experimental conditions. The conjunction of complex life cycles, which can last up two years [37], exceeding the duration of the follow-up period in this study, and the larger average size body that characterizes most of the members of this family could explain this result.

The remaining taxa obtained during the follow-up of the branches have been found scarcely and randomly in the different trials, so that the data does not allow for definitive results.

Finally, considering the joint effect of environmental traits and land management on saproxylic diversity, the results of the multivariate analysis do not indicate a clear relationship.

Several studies have analyzed the degree to which the characteristics and management of the forest affect the diversity of species of saproxylic beetles. A positive relationship between the diameter (and consequently the age) of the trees and the richness of these insects has been obtained [45,66,67]. This factor was not considered in our research. Detailed study of each factor considered and the diversity of the saproxylic families suggests that tree density is the most determining factor, agreeing with Ramilo [48], who obtained lower wealth of saproxylic beetles in areas with high plant density. The statement on this concern is not definitive: Some authors have detected a direct association between saproxylic richness and the presence of green cover $[68,69]$, while others have observed a higher richness in meadows with little bush cover [4].

Although the amount of dead wood accumulated in the soil of each sampling plot was not quantified in our study, field observations suggest that the effect of the accumulation of fallen branches favors the presence not only of saproxylic fauna, but of other taxa that use this resource as a refuge, agreeing with Lachat [70]. Furthermore, other authors have mentioned that not only quantity, but also the decomposition degree of the fallen wood intervenes on the greatest faunistic affluence [71,72].

Therefore, the regulation of the amount of wood to be removed from Mediterranean forests is a crucial issue for the conservation of its biodiversity. This fact is at odds with some of the traditional uses of the dehesa: Wood production and logging. Current conservation and sustainability trends support management models avoiding removal of large quantities of wood [6,73]. However, and for areas of mixed Mediterranean forest, the amount necessary to keep guaranteeing the availability for saproxylic organisms is unknown today $[46,73,74]$. More research is required to provide adequate advice on land management for comprehensive conservation of the Iberian dehesas.

Supplementary Materials: The following are available online at http://www.mdpi.com/1424-2818/12/12/451/s1, Table S1. Species of saproxylic beetles recorded through the monitoring of the branches in all sampling plots. The asterisk ${ }^{*}$ ) indicates that the species is under some protection figure. Table S2. Post- hoc test corresponding to the GLMM analyses performed using tree species as Categorical Factor and sampling plot as Random Factor. CS: C. siliqua; OE: O. europea; QI: Q. ilex; QS: Q. suber; S. D.: Standard Deviation; S.E.: Standard Error; Different uppercase letters indicate significant differences among tree species according to the Post-hoc tests $(p$-value $<$ 0.05). Table S3. Simple logistic model coefficients for the Buprestidae, Bostrichidae and Cerambycidae Families: VAR: variable; A: Altitude; S: Slope; O: Orientation; SL: Shrub Layer; D: Tree Density; LV: Livestock; LU: Land Use; K: Constant; B: regression coefficient; SE: Standard Error; P: statistical significance; Exp ( $\beta$ ): "odds ratio". Supplementary material 3. Table S4. Simple logistic model coefficients for the Carabidae and Cleridae Families: VAR: Variable, A: Altitude; S: Slope; O: Orientation; SL: Shrub Layer; D: Tree Density; LV: Livestock; LU: Land Use; K: Constant; B: regression coefficient; SE: Standard Error; P: statistical significance; Exp ( $\beta$ ): “odds ratio". Table S5. Multivariant logistic model coefficients for the Buprestidae, Bostrichidae, Cerambycidae, Carabidae and Cleridae Families. VAR: Variable; A: Altitude; S: Slope; O: Orientation; SL: Shrub Layer; D: Tree Density; LV: Livestock; LU: Land Use; B: regression coefficient; SE: Standard Error; P: statistical significance; Exp ( $\beta$ ): "odds ratio". Table S6. Temporal distribution (from January to July) of saproxylic species emerged in Trial 1. Table S7. Temporal distribution (from January to July) of saproxylic species emerged in Trial 2. Table S8. Temporal distribution (from January to July) of saproxylic species emerged in Trial 3. Table S9. Temporal distribution (from January to July) of saproxylic species emerged in Trial 4.

Author Contributions: A.M.C. and P.G. participated in the conceptualization, design, and methodology of field sampling; A.M.C. made the original draft preparation and text edition; Á.S. and J.M. participated in field sampling and recording data. All authors have read and agreed to the published version of the manuscript.

Funding: This research received no external funding. 
Acknowledgments: We thank Sutcliffe for the language revision.

Conflicts of Interest: The authors declare no conflict of interest.

\section{References}

1. Myers, N.; Mittermeier, R.A.; Mittermeier, C.G.; Da Fonseca, G.; Kent, J. Biodiversity hotspots for conservation priorities. Nature 2000, 403, 853-858. [CrossRef]

2. Campos, P.; Huntsinger, L.; Oviedo, J.L.; Starrs, P.F.; Diaz, M.; Standiford, R.B.; Montero, G. Mediterranean Oak Woodland Working Landscapes; Landscapes Series; Springer: Dordrecht, The Netherlands, 2013; pp. 61-89.

3. Bugalho, M.N.; Caldeira, M.; Pereira, J.; Aronson, J.; Pausas, J. Mediterranean cork oak savannas require human use to sustain biodiversity and ecosystem services. Front. Ecol. Environ. 2011, 9, 278-286. [CrossRef]

4. Ramírez-Hernández, A.; Micó, E.; Galante, E. Temporal variation in saproxylic beetle assemblages in a Mediterranean ecosystem. J. Insect Conserv. 2014, 18, 993-1007. [CrossRef]

5. Stokland, J.N.; Siitonen, J.; Jonsson, B.G. Biodiversity in Dead Wood. Ecology, Biodiversity, and Conservation; Cambridge University Press: Cambridge, UK, 2012; pp. 218-269.

6. Davies, Z.G.; Tyler, C.; Stewart, G.B.; Pullin, A.S. Are current management recommendations for saproxylic invertebrates effective? A systematic review. Biodivers. Conserv. 2008, 17, 209-234. [CrossRef]

7. Quinto, J.; Micó, E.; Martínez-Falcón, A.P.; Galante, E.; Marcos-García, M.A. Influence if tree hollow characteristics on the diversity of saproxylic insect guilds in Iberian Mediterranean woodlands. J. Insect Conserv. 2014, 18, 981-992. [CrossRef]

8. Pérez-Moreno, I. Nuevas aportaciones al conocimiento de la fauna de Coleópteros saproxílicos (Coleoptera) del Sistema Ibérico Septentrional, I. Robledales del Valle Medio del Iregua (Sierra de Cameros, La Rioja, España). Bol. S.E.A. 2010, 46, 321-334.

9. Horák, J.; Chobot, K.; Chumanová, E. Habitat preferences influencing populations, distribution, and conservation of the endangered saproxylic beetle Cucujus cinnaberinus (Coleoptera: Cucujidae) at the landscape level. Eur. J. Entomol. 2010, 107, 81-88. [CrossRef]

10. Horák, J.; Chumanová, E.; Hilszczaoski, J. Saproxylic beetle thrives on the openness in management: A case study on the ecological requirements of Cucujus cinnaberinus from Central Europe. Insect Conserv. Divers. 2011, 5, 403-413. [CrossRef]

11. Nieto, A.; Alexander, K.N.A. European Red List of Saproxylic Beetles; Publications Office of the European Union: Luxembourg, 2010; p. 46.

12. Radenkovid, S. The saproxylic hoverflies (Diptera: Syrphidae) of Serbia. J. Nat. Hist. 2013, 47, 87-127. [CrossRef]

13. Cavalli, R.; Mason, F. Techniques for Reestablishment of Dead Wood for Saproxylic Fauna Conservation; LIFE nature project NAT/IT/99/6245 Bosco della Fontana (Mantova, Italy); Gianluigi Arcari Editore: Mantova, Italy, 2003; p. 109.

14. Gallardo, P.; Cárdenas, A.M. Long term monitoring of saproxylic beetles from Mediterranean oak forests: An approach to the larval biology of the most representative species. J. Insect Conserv. 2016, 20, 999-1009. [CrossRef]

15. DEFRA (Department for Environment, Food and Rural Affairs). Natural Environment, Adapting to Climate Change; Department for Environment, Food and Rural Affairs: London, UK, 2010; p. 51.

16. Maresi, G.; Salvadori, C. Crown conditions and damages in two forest ecosystems in Trentino (Italy), Studi Trent. Sci. Nat. Acta Biol. 2005, 81, 253-260.

17. Pardos, J.A. La contaminación atmosférica y los ecosistemas forestales. Forest Syst. 2006, 15, 55-70.

18. Freer-Smith, P.H.; Broadmeadow, M.S.J.; Lynch, J.M. Forest, and climate change: The knowledgebase for action. In Forestry and Climate Change; Freer-Smith, P.H., Broadmeadow, M.S.J., Lynch, J.M., Eds.; CAB International: Wallingford, UK, 2007.

19. Benito-Garzón, M.; Dios, R.S.; Sainz-Ollero, H. Effects of climate change on the distribution of Iberian tree species. Appl. Veg. Sci. 2008, 11,1-10. [CrossRef]

20. Myers, S.W.; Fraser, I.; Mastro, V.C. Evaluation of heat treatment schedules for emerald ash borer (Coleoptera: Buprestidae). J. Econ. Entomol. 2009, 102, 2048-2055. [CrossRef]

21. Sobek, S.; Rajamohan, A.; Dillon, D.; Cumming, R.C.; Sinclair, B.J. High temperature tolerance and thermal plasticity in emerald ash borer Agrilus Planipennis Agr. Forest Entomol. 2011, 13, 333-340. [CrossRef] 
22. Cárdenas, A.; Gallardo, P. The effect of temperature on the preimaginal development of the Jewel beetle Coraebus florentinus (Coleoptera: Buprestidae). Eur. J. Entomol. 2012, 109, 21-28. [CrossRef]

23. Cárdenas, A.M.; Gallardo, P. The effects of oviposition on the development of the wood borer Coraebus florentinus (Coleoptera: Buprestidae). Eur. J. Entomol. 2013, 110, 135-144. [CrossRef]

24. Mushrow, L.; Morrison, A.; Sweeney, J.; Quiring, D. Heat as a phytosanitary treatment for the brown spruce longhorn beetle. Forest. Chron. 2004, 80, 224-228. [CrossRef]

25. Bains, S.S. Effect of temperature and moisture on the biology of Rhyzopertha dominica Fabricius (Bostrichidae: Coleoptera). Bull. Grain Technol. 1971, 9, 257-264.

26. Ostaff, D.P.; Cech, M.Y. Heat Sterilization of Spruce-Pine-Fir Lumber Containing Pine Sawyer Beetle Larvae (Coleoptera: Cerambycid monochamus); Rep. OPX-200E; Canadian Forest Service: Ottawa, ON, Canada, 1978; p. 15.

27. Faroni, L.R.A.; García-Mari, F. Influencia de la temperatura sobre los parámetros biológicos de Rhyzopertha dominica (F.). Bol. San. Veg. Plagas 1992, 18, 455-467.

28. Cárdenas, A.M.; Gallardo, P. Assessment and monitoring damage by Coraebus florentinus (Coleoptera: Buprestidae) in Mediterranean oak forests. Open J. Ecol. 2018, 8, 324-338. [CrossRef]

29. Song, W.; Mu, X.; Ruan, G.; Gao, Z.; Li, L.; Yan, G. Estimating fractional vegetation cover and the vegetation index of bare soil and highly dense vegetation with a physically based method. Int. J. Appl. Earth Obs. 2017, 58, 168-176. [CrossRef]

30. Henderson, P.A. Practical Methods in Ecology; Blackwell Publishing: Cambridge, UK, 2003; p. 15.

31. Bahillo de la Puebla, P.; López-Colón, J.I. Cléridos de Andalucía (Coleoptera, Cleridae); Delegación de Cultura del Excmo. Ayuntamiento de Utrera; Fundación El Monte y Sociedad Andaluza de Entomología: Utrera, Sevilla, 2001; p. 71.

32. de la Puebla, P.B.; López-Colón, J.I.; García-París, M. Una especie nueva de Tillus Olivier, 1790 (Coleoptera, Cleridae) de la Península Ibérica. Graellsia 2003, 59, 57-62.

33. Cobos, A. Fauna Ibérica de coleópteros Buprestidae; CSIC: Madrid, Spain, 1986; p. 364.

34. Verdugo, A. Fauna de Buprestidae de la Península Ibérica y Baleares; Argania Editio: Barcelona, Spain, 2005; p. 350.

35. Ortuño, V.M.; Toribio, M. Carabidae de la Península Ibérica y Baleares; Volume I. Trechinae, Bembidiini; Argania Editio: Barcelona, Spain, 2005; p. 455.

36. Villiers, A. Faune des Coléoptères de France. I Cerambycidae; Editions Lechevalier: Paris, France, 1978; p. 611.

37. Vives, E. Coleoptera Cerambycidae; Fauna Ibérica; Volume 12; CSIC: Madrid, Spain, 2000; p. 716.

38. Bahillo de la Puebla, P.; López-Colón, J.I.; Baena, M. Los Bostrichidae Latreille 1802 de la fauna íbero-balear (Coleoptera). Heteropterus Rev. Entomol. 2007, 7, 147-227.

39. Rochowicz, J.A. Bootstrapping analysis, inferential statistics, and EXCEL. Spreadsheets Education (eJSiE) 2011, 4, 1-23.

40. Southwood, T.R.E.; Henderson, P.A. Ecological Methods, 3rd ed.; Blackwell Science Ltd.: Cambrige, UK, 2000; p. 592.

41. Çokluk, Ö. Logistic regression: Concept and application. Educ. Sci. Theory Pract. 2010, 10, 1397-1407.

42. McDonald, J.H. Handbook of Biological Statistics; Sparky House Publishing: Baltimore, MD, USA, $2014 ;$ p. 299.

43. SPSS Inc. SPSS 14.0 for Windows Use Manual; SPSS Inc.: Chicago, IL, USA, 2006; p. 473.

44. PAST Inc. PAST 3.25 for Windows Use Manual, (version 3.25); PAST Inc.: Oslo, Norway, 2017; p. 259.

45. Grove, S. Saproxylic insect ecology and the sustainable management of forests. Annu. Rev. Ecol. Evol. Syst. 2002, 33, 1-23. [CrossRef]

46. Jonsson, B.G.; Kruys, N.; Raniuset, T. Ecology of species living on dead wood: Lessons for dead-wood management. Silva Fenn. 2005, 39, 289-389. [CrossRef]

47. Peris-Felipo, F.J.; Jiménez-Peydró, R. Cerambycidae (Coleoptera) richness in Mediterranean landscapes of Spain: Diversity and community structure analysis. Biodivers. J. 2012, 3, 59-68.

48. Ramilo, P. La Comunidad de Coleópteros Saproxílicos en Bosque Mediterráneo: Factores Ambientales que Condicionan sus Ensambles. Ph.D. Dissertation, University of Alicante, Alicante, Spain, 2018; p. 52. Available online: http://hdl.handle.net/10045/86894 (accessed on 14 July 2020).

49. Luna-Murillo, A.; Obregón, R. Nuevas aportaciones a la fauna de Bostrichidae (Coleoptera) de la provincial de Córdoba (Andalucía, España). Bol. Soc. Andaluza Ent. 2013, 21, 46-57. 
50. Nardi, G.; Mifsud, D.A. The Bostrichidae of the Maltese Islands (Coleoptera). ZooKeys 2015, 481, 69-108. [CrossRef] [PubMed]

51. Sverdrup-Thygeson, A.; Birkemoe, T. What window traps can tell us: Effect of placement, forest openness and beetle reproduction in retention trees. J. Insect Conserv. 2009, 13, 183-191. [CrossRef]

52. Horák, J.; Chobot, K.; Horáková, J. Hanging on by the tips of the tarsi: A review of the plight of the critically endangered saproxylic beetle in European forests. J. Nat. Conserv. 2012, 20, 101-108. [CrossRef]

53. Widerberg, M.K.; Ranius, T.; Drobyshev, I.; Nilsson, U.; Lindbladh, M. Increased openness around retained oaks increases richness of saproxylic beetles. Biodivers. Conserv. 2012, 21, 3035-3059. [CrossRef]

54. Micó, E.; García-López, A.; Sánchez, A.; Juárez, M.; Galante, E. What can physical, biotic and chemical features of a three hollow tell us about their associated diversity? J. Insect Conserv. 2015, 19, 141-153. [CrossRef]

55. Recalde, J.I.; San Martín, A.F. Coleópteros xilófagos asociados a ramas de Quercus muertas por la acción del bupréstido Coraebus florentinus (Herbst, 1801) en la Navarra media. Heteropterus Rev. Ent. 2003, 3, 43-50.

56. Lindner, M.; Maroschek, M.; Netherer, S.; Kremer, A.; Barbati, A.; Garcia-Gonzalo, J.; Seidl, R.; Delzon, S.; Corona, P.; Kolström, M.; et al. Climate change impacts, adaptative capacity and vulnerability of European forest ecosystems. Forest Ecol. Manag. 2010, 259, 698-709. [CrossRef]

57. Netherer, S.; Schopf, A. Potential effects of climate change on insect herbivores in European forests-general aspects and the pine processionary moth as specific example. Forest Ecol. Manag. 2010, 259, 831-838. [CrossRef]

58. Alexander, K.N.A. Changing distribution of Cantharidae and Buprestidae within Great Britain (Coleoptera). In Proceedings of the 13th International Colloquium of the European Invertebrate Survey, Leiden, The Netherlands, 2-5 September 2003; Reemer, M., van Helsdingen, P.S., Kleukes, R.M., Eds.; European Invertebrate Survey: Leiden, The Netherlands, 2001; pp. 87-91.

59. Tauber, M.J.; Tauber, C.A.; Masaki, S. Seasonal Adaptations of Insects; Oxford University Press: New York, NY, USA, 1986; p. 411.

60. Gaylord, M.L.; Kolb, T.E.; Wallin, F.K.; Wagner, M.R. Seasonality, and lure preference of bark beetles (Curculionidae: Scotylinae) and associates in a Northern Arizona ponderosa pine forest. Environ. Entomol. 2006, 35, 3747. [CrossRef]

61. Stork, N.E.; Hammond, P.M. Species richness and temporal partitioning in the beetle fauna of oak trees (Quercus robur L.) in Richmond Park, UK. Insect Conserv. Diver. 2013, 6, 67-81. [CrossRef]

62. Powell, J.A.; Logan, J.A. Insect seasonality: Circle map analysis of temperature driven life cycles. Theor. Popul. Biol. 2005, 67, 161-179. [CrossRef] [PubMed]

63. Haack, R.A.; Slansky, F.J. Nutritional ecology of Wood-feeding Coleoptera, Lepidoptera and Hymenoptera. In Nutrition Ecology of Insects, Mites, Spiders, and Related Invertebrates; Slansky, F.J., Rodríguez, J.E., Eds.; Wiley-Interscience: New York, NY, USA, 1985; pp. 449-486.

64. Walczyńska, A.; Danko, M.; Kozłowski, J. The considerable adult size variability in wood feeders is optimal. Ecol. Entomol. 2010, 35, 16-24. [CrossRef]

65. Scriven, J.J.; Whitehorn, P.R.; Goulson, D.; Tinsley, M.C. Bergmann's body size rule operates in facultatively endothermic insects: Evidence from a complex of cryptic bumblebee species. PLoS ONE 2016, 11, e0163307. [CrossRef] [PubMed]

66. Jonsell, M.; Weslien, J.; Ehnström, B. Substrate requirements of red-listed saproxylic invertebrates in Sweden. Biodivers. Conserv. 1998, 7, 749-764. [CrossRef]

67. Ranius, T.; Jansson, N. The influence of forest regrowth, original canopy cover and tree size on saproxylic beetles associated with old oaks. Biol. Conserv. 2000, 95, 85-94. [CrossRef]

68. Økland, B.A. Comparison of three methods of trapping saproxylic beetles. Eur. J. Entomol. 1996, 93, 195-209.

69. Janssen, P.; Fortin, D.; Hébert, C. Beetle diversity in a matrix of old-growth boreal forest: Influence of habitat heterogeneity at multiple scales. Ecography 2009, 32, 423-432. [CrossRef]

70. Lachat, T. Deadwood: Quantitative and qualitative requirements for the conservation of saproxylic biodiversity. In Integrative Approaches as an Opportunity for the Conservation of Forest Biodiversity; Kraus, D., Krumm, F., Eds.; European Forest Institute: Freiburg, Germany, 2013; p. 284.

71. Brin, A.; Brustel, H.; Jactel, H. Species variables or environmental variables as indicators of forest biodiversity: A case study using saproxylic beetles in Maritime pine plantations. Ann. For. Sci. 2009, 66, 306. [CrossRef] 
72. Lassauce, A.; Paillet, Y.; Jactel, H.; Bouget, C. Deadwood as a surrogate for forest biodiversity: Meta-analysis of correlations between deadwood volume and species richness of saproxylic organism. Ecol. Indic. 2011, 11, 1027-1039. [CrossRef]

73. Gustafsson, L.; Baker, S.C.; Bauhus, J.; Beese, W.J.; Brodie, A.; Kouki, J.; Lindenmayer, D.B.; Lõhmus, A.; Martínez-Pastur, G.; Messier, C. Retention forestry to maintain multifunctional forests: A world perspective. Bioscience 2012, 62, 633-645. [CrossRef]

74. Méndez-Iglesias, M. ¿Cómo gestionar la madera muerta y conservar a los organismos saproxílicos? Quercus 2014, 336, 32-38.

Publisher's Note: MDPI stays neutral with regard to jurisdictional claims in published maps and institutional affiliations.

(C) 2020 by the authors. Licensee MDPI, Basel, Switzerland. This article is an open access article distributed under the terms and conditions of the Creative Commons Attribution (CC BY) license (http://creativecommons.org/licenses/by/4.0/). 